Article

\title{
Novel (1E,3E,5E)-1,6-bis(Substituted phenyl)hexa-1,3,5-triene Analogs Inhibit Melanogenesis in B16F10 Cells and Zebrafish
}

\author{
Jisun Oh ${ }^{1}$, Jungeun Kim ${ }^{1}$, Jin Ho Jang ${ }^{1}$, Sangwoo Lee ${ }^{2}$, Chul Min Park ${ }^{3}$, Woo-Keun Kim ${ }^{2, *}$ \\ and Jong-Sang Kim ${ }^{1, *}$ iD \\ 1 School of Food Science and Biotechnology (BK21 Plus), Kyungpook National University, \\ Daegu 41566, Korea; j.oh@knu.ac.kr (J.O.); astely88@hanmail.net (J.K.); mk5266@naver.com (J.H.J.) \\ 2 System Toxicology Research Center, Korea Institute of Toxicology, Daejeon 34114, Korea; \\ sangwoo.lee@kitox.re.kr \\ 3 Center for Convergent Research of Emerging Virus Infection, Korea Research Institute of Chemical \\ Technology, Daejeon 34114, Korea; parkcm@krict.re.kr \\ * Correspondence: wookkim@kitox.re.kr (W.-K.K.); vision@knu.ac.kr (J.-S.K.); \\ Tel.: +82-42-610-8305 (W.-K.K.); +82-53-950-5752 (J.-S.K.); Fax: +82-53-950-6750 (J.-S.K.)
}

Received: 30 January 2018; Accepted: 30 March 2018; Published: 3 April 2018

\begin{abstract}
The present study aimed to evaluate the anti-melanogenic activity of 1,6-diphenyl-1,3,5-hexatriene and its derivatives in B16F10 murine melanoma cells and zebrafish embryos. Twenty five ( $1 E, 3 E, 5 E)$-1,6-bis(substituted phenyl)hexa-1,3,5-triene analogs were synthesized and their non-cytotoxic effects were predictively analyzed using three-dimensional quantitative structure-activity relationship approach. Inhibitory activities of these synthetic compounds against melanin synthesis were determined by evaluating melanin content and melanogenic regulatory enzyme expression in B16F10 cells. The anti-melanogenic activity was verified by observing body pigmentation in zebrafishes treated with these compounds. Compound \#2, \#4, and \#6 effectively decreased melanogenesis induced by $\alpha$-melanocyte-stimulating hormone. In particular, compound \#2 remarkably lowered the mRNA and protein expression levels of microphthalmia-associated transcription factor (MITF), tyrosinase (TYR), tyrosinase-related protein 1 (TYRP1), and TYRP2 in B16F10 cells and substantially reduced skin pigmentation in the developed larvae of zebrafish. These findings suggest that compound \#2 may be used as an anti-melanogenic agent for cosmetic purpose.
\end{abstract}

Keywords: synthetic compound; anti-melanogenesis; melanocyte; zebrafish; pigmentation

\section{Introduction}

Melanin is a dark pigment produced through melanogenesis, a natural phenomenon occurring by the action of tyrosinase in melanocytes [1]. Tyrosinase converts tyrosine to L-3,4-dihydroxyphenylalanine (L-DOPA), dopaquinone, dopachrome, and subsequently to melanin. Upon the exposure of the skin to external stimuli such as ultraviolet light, air pollution, and oxidative stress, melanin pigments are excessively produced within melanocytes. The pigments are then transferred to the keratinocytes and, thus, accumulate in the epidermal layer of the skin, which consequently causes skin darkening and cancer [2-4]. Therefore, the prevention of melanin synthesis in melanocytes for the improvement of skin health is commonly studied based on the following three criteria: (i) development of tyrosinase inhibitors; (ii) development of bioactive chemicals that are toxic to melanocytes; and (iii) development of DOPA-reducing substances to prevent the oxidation of intermediate metabolites in the melanogenic pathway $[5,6]$. 
Given that tyrosinase is the key enzyme in melanin synthesis that exclusively occurs in melanocytes, melanogenesis may be effectively inhibited by antagonizing the catalytic activity and/or biosynthesis of tyrosinase [5-9]. Most commercially available skin-whitening agents are tyrosinase inhibitors [9-11] such as kojic acid [12], arbutin [13], hydroquinone [14], ellagic acid [15], and their derivatives. All of these have drawbacks, including carcinogenicity, chemical instability, and poor bioavailability $[9,10]$.

$\mathrm{Ha}$ and coworkers have recently synthesized a variety of triene analogs as potential tyrosinase inhibitors and examined the structure-activity relationship between mushroom tyrosinase and these synthesized compounds [16]. These authors found that certain triene derivatives, including 4,4'-((1E,3E,5E)-hexa-1,3,5-triene-1,6-diyl)diphenol, 5,5'-((1E,3E,5E)-hexa-1,3,5-triene-1,6-diyl)bis(2-methoxy-phenol), and 5,5'-((1E,3E,5E)-hexa-1,3,5-triene1,6-diyl)dibenzene-1,3-diol, may possibly act as pharmacophores in the process of tyrosinase inhibition. In the present study, we evaluated the potential anti-melanogenic effect of novel synthetic triene analogs-1,6-diphenyl-1,3,5-hexatriene and its derivatives, using B16F10 murine melanoma cells and zebrafish embryos.

\section{Results}

\subsection{Synthesis of Novel Compounds}

A total of 25 compounds were synthesized [16] and their chemical identifies are presented in Supplementary Figure S1 and Supplementary Table S1. Results of the in silico analysis using QSAR method showed that all the compounds had no predicted toxicity, as observed from the test for sensitization and skin irritation.

\subsection{Cytotoxicity of the Compounds}

The compounds were examined for their cytotoxicities. Murine melanoma B16F10 cells were treated with each compound at various concentrations $(0,1.6,3.1,6.25$, and $12.5 \mu \mathrm{M})$. After $24 \mathrm{~h}$ of incubation, the cell viability was assayed using CCK-8 kit (Figure 1). The majority of compounds, including \#2, \#3, \#4, \#6, \#10, \#11, \#13, \#14, \#15, \#16, \#17, \#18, \#20, \#21, \#22, \#23, and \#24, showed negligible toxicity at the maximum concentration of $12.5 \mu \mathrm{M}$. Eight compounds (\#1, \#5, \#7, \#8, \#9, \#12, \#19, and \#25) were found to be cytotoxic. The compounds with little cytotoxicity were further analyzed for melanogenesis inhibition activity.

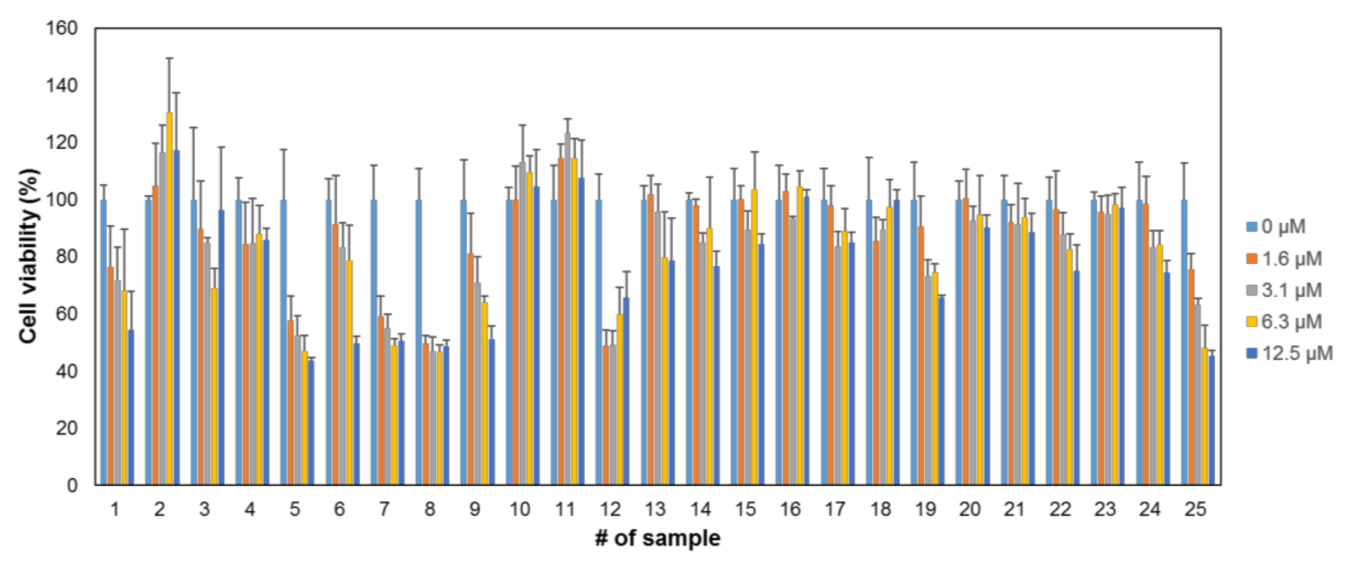

Figure 1. Cytotoxicity of novel synthetic compounds. B16F10 murine melanoma cells were treated with each compound at various concentrations $(0,1.6,3.1,6.3$, and $12.5 \mu \mathrm{M})$ for $24 \mathrm{~h}$. CCK-8 assay was performed to assess the cytotoxic effect. $n=3$; error bars, mean $\pm \mathrm{SD}$. 


\subsection{In Vitro Anti-Melanogenic Effect of the Compounds}

To investigate the melanogenesis inhibition effect of the non-cytotoxic synthetic compounds (Supplementary Figure S2), B16F10 cells were stimulated with $\alpha$-MSH $(10 \mathrm{nM})$ and simultaneously treated with each compound at either 1 or $5 \mu \mathrm{M}$ concentration. After $72 \mathrm{~h}$ of treatment, relative melanin content produced in the cells was spectrophotometrically measured. Among the compounds, \#2, \#4, \#6, \#15, and \#17 decreased the melanin content and were chosen for verification by testing at either 1 or $2 \mu \mathrm{M}$. The compounds, \#2, \#4,\#6, and \#17 were found to inhibit $\alpha$-MSH-induced melanin production in a concentration-dependent manner (Figure 2). In particular, compound \#2, \#4, and \#6 significantly inhibited melanogenesis in B16F10 cells at $1 \mu \mathrm{M}$ concentration in the presence of $\alpha$-MSH. The chemical structure of each of the three compounds is shown in Figure 3. These compounds were used for further examinations.

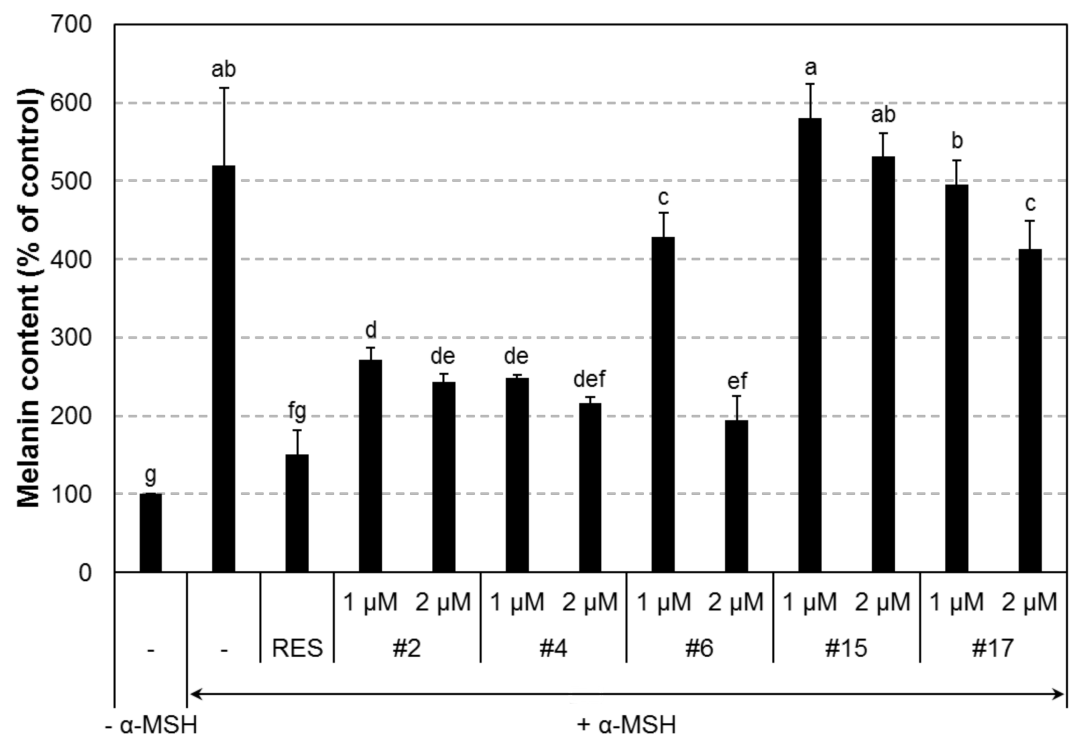

Figure 2. In vitro anti-melanogenic activity of compound \#2, \#4, \#6, \#15, and \#17. B16F10 cells were cultured in the presence of various compounds at 1 or $2 \mu \mathrm{M}$ concentration and/or $\alpha-\mathrm{MSH}$ at $10 \mathrm{nM}$ for $72 \mathrm{~h}$. Cellular melanin content decreased following treatment with these compounds in a dose-dependent manner. $\alpha$-MSH, alpha-melanocyte-stimulating hormone $(10 \mathrm{nM})$. RES, resveratrol $(10 \mu \mathrm{M}) . n=3$; error bars, mean \pm SEM. Different alphabetical letters indicate significant differences among the conditions $(p<0.05)$.

(A)

Compound \#2

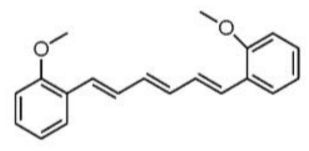

(B)

Compound \#4

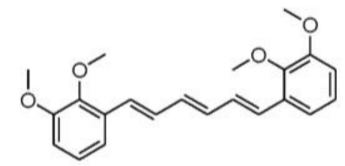

(C)

Compound \#6

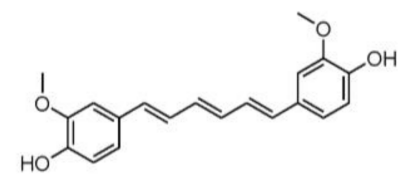

Figure 3. Chemical structure of anti-melanogenic compounds \#2 (A), \#4 (B), and \#6 (C).

\subsection{Tyrosinase Inhibition Activity of the Selected Compounds}

The three selected compounds, \#2, \#4, and \#6, were further examined for tyrosinase inhibition activity using mushroom tyrosinase (Figure 4) or using crude tyrosinase extract from B16F10 cells (Supplementary Figure S3). Kojic acid, a well-known tyrosinase inhibitor, was used as a positive control. The result demonstrated that the compounds \#2 and \#4 effectively inhibited the catalytic activity of 
tyrosinase and their inhibitory effects were comparable to the effect of kojic acid at concentrations of $\leq 12.5 \mu \mathrm{M}$.

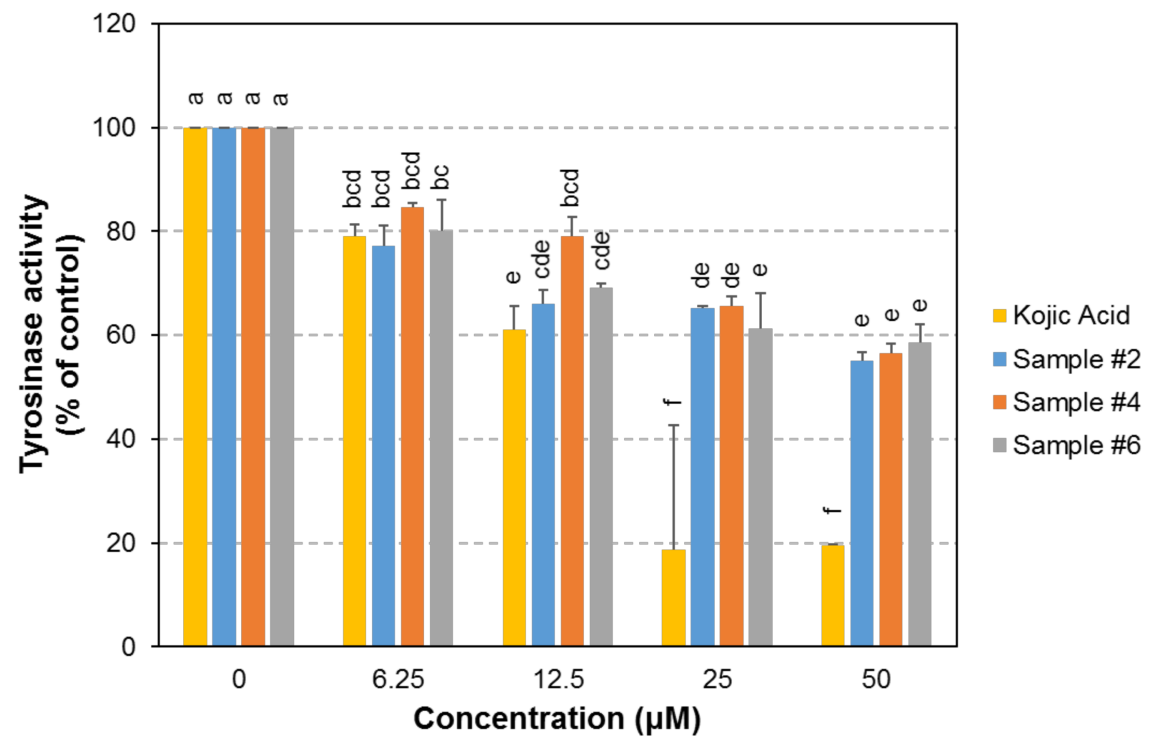

Figure 4. Tyrosinase inhibitory effect of compound \#2, \#4, and \#6. Catalytic activity of the mushroom tyrosinase was measured in the presence of each compound at various concentrations $(0,6.25,12.5$, 25, and $50 \mu \mathrm{M})$. Kojic acid, a well-known tyrosinase inhibitor, was used as a positive control. $n=3$; error bars, mean \pm SEM. Different alphabetical letters indicate significant differences among the conditions $(p<0.05)$.

\subsection{Inhibition of the Transcript and Protein Expression of MITF and Melanogenic Enzymes}

The effects of the selected compounds on the expression of mRNA encoding melanogenic factors were evaluated in $\alpha$-MSH-stimulated B16F10 cells. Total mRNAs were extracted from the cells treated with $\alpha-\mathrm{MSH}$ in the absence or presence of each compound. The mRNA levels of tyrosinase (Tyr), tyrosinase-related protein 1 (Tyrp1), Tryp2, and microphthalmia-associated transcription factor (Mitf) were quantified by real-time PCR (Figure 5). The mRNA levels of Tyr, Tyrp1, Tryp2, and Mitf induced by $\alpha$-MSH were effectively suppressed in the presence of compounds \#2 and \#4.
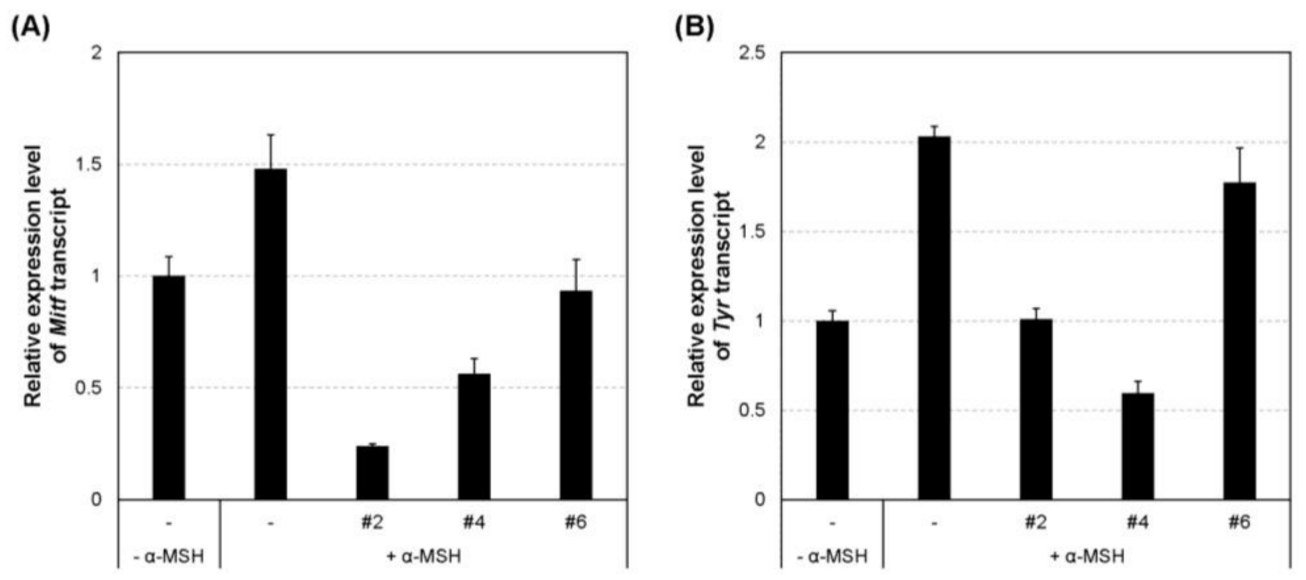

Figure 5. Cont. 
(C)

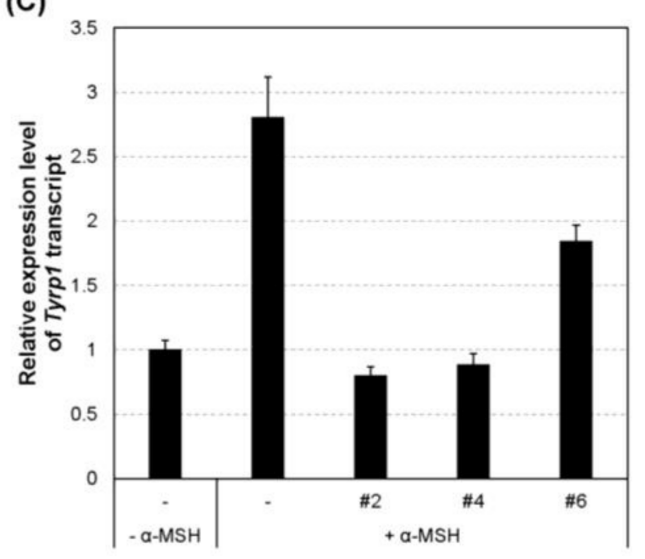

(D)

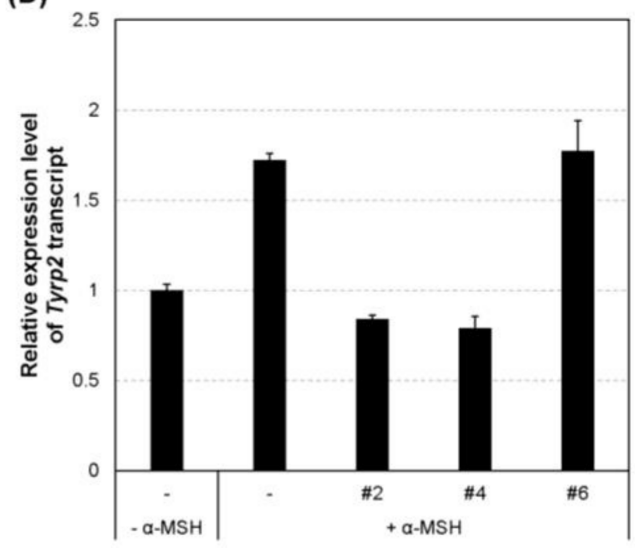

Figure 5. Relative mRNA transcript levels of melanogenic genes Mitf, Tyr, Tyrp1, and Tryp2. (A) Mitf mRNA level; (B) Tyr mRNA level; (C) Tyrp1 mRNA level; (D) Tyrp2 mRNA level. B16F10 cells were treated with one of three compounds (\#2, \#4, and \#6) at $2 \mu \mathrm{M}$ for $24 \mathrm{~h}$. The relative mRNA levels for indicated genes in the cells were quantified using SYBR green-based real-time PCR and normalized to the $\beta$-actin mRNA level. The information of primer sets is shown in Table 1. $\alpha$-MSH, $\alpha$-melanocyte-stimulating hormone; Mitf, microphthalmia-associated transcription factor; Tyr, tyrosinase; Tyrp1, tyrosinase-related protein 1; Tryp2, tyrosinase-related protein 2.

The expression level of melanogenic proteins in B16F10 cells was examined by Western blot analysis (Figure 6). The intracellular levels of TYR, TYRP1, and TRYP2 were markedly increased in $\alpha$-MSH-treated cells and greatly reduced by concomitant treatment with compound \#2. However, compounds \#4 and \#6 were ineffective in suppressing $\alpha$-MSH-induced expression of TYR and TYRP1; however, compound \#6 induced a prominent inhibition of TYRP2 expression.

(A)

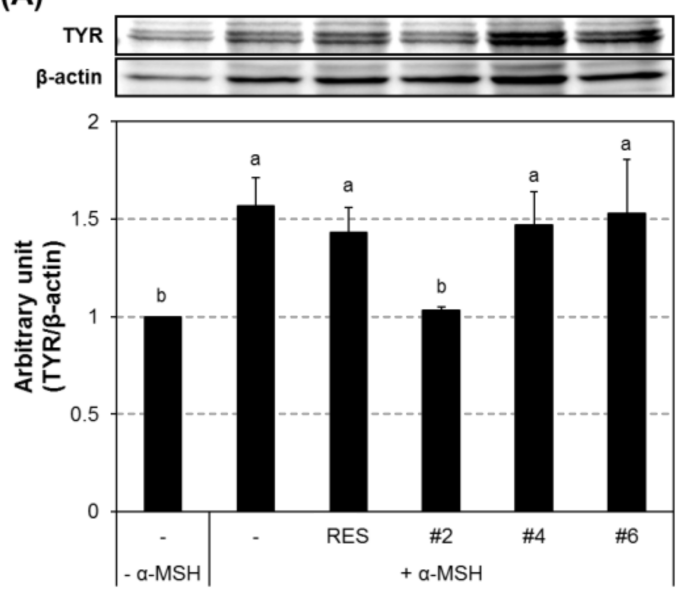

(B)

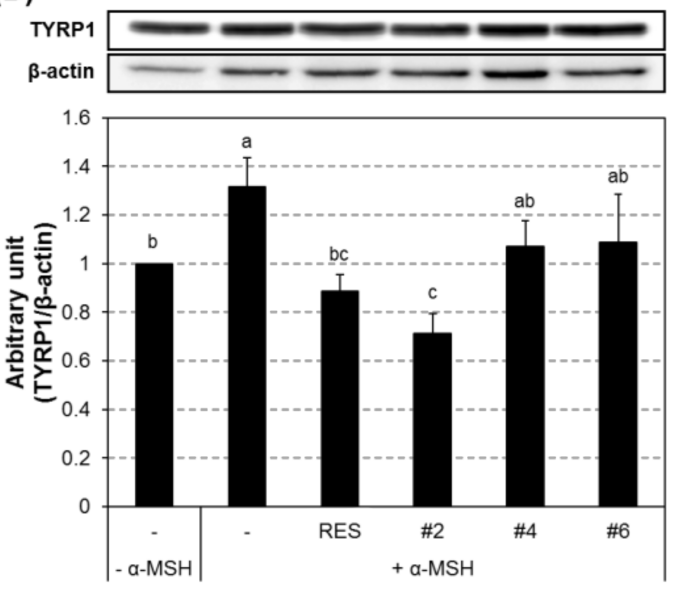

Figure 6. Cont. 
(C)

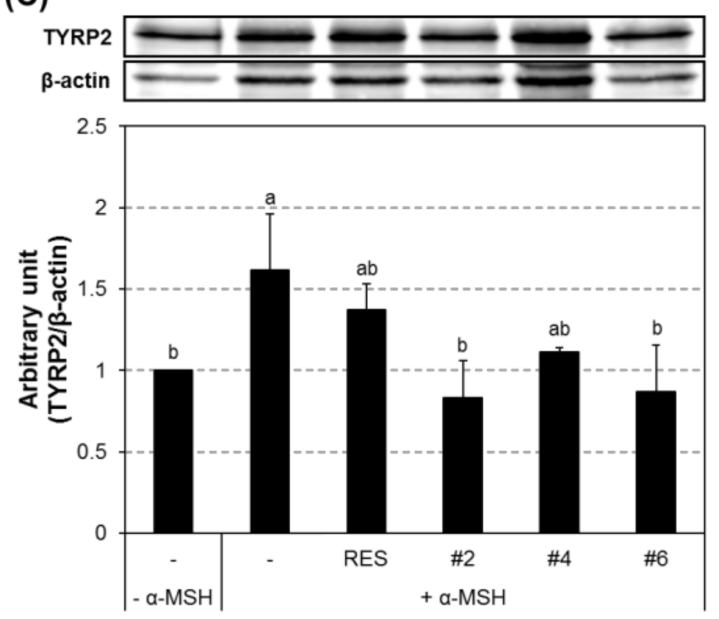

Figure 6. Melanogenic protein expression in the compound-treated B16F10 cells. The cells were treated with the indicated compound at $2 \mu \mathrm{M}$ concentration for $24 \mathrm{~h}$. Relative protein expression levels of cytoplasmic TYR (A), TYRP1 (B), and TYRP2 (C) were determined by western blot analysis. $\alpha$-MSH, alpha-melanocyte-stimulating hormone (10 nM); RES, resveratrol (10 $\mu \mathrm{M})$; TYR, tyrosinase; TYRP1, tyrosinase-related protein 1; TRYP2, tyrosinase-related protein 2. $n=3$; error bars, mean \pm SEM. Different alphabetical letters indicate significant differences among the conditions $(p<0.05)$.

\subsection{Depigmentation in Zebrafish Exposed to Compound \#2}

The anti-melanogenic activity of compound \#2, which was most effective in B16F10 cells, was tested in the zebrafish model. Zebrafishes were exposed to either arbutin or compound \#2 at concentrations ranging from 0 to $1000 \mu \mathrm{g} / \mathrm{L}$ for $72 \mathrm{~h}$ and the pigmentation on the skin was stereomicroscopically observed (Figure 7A,B). The skin exposed to compound \#2 showed significant depigmentation at 500 and $1000 \mu \mathrm{g} / \mathrm{L}$ (Figure 7C,D). The exposure to compound \#2 at the tested doses failed to affect the viability or activity of zebrafish.

(A)
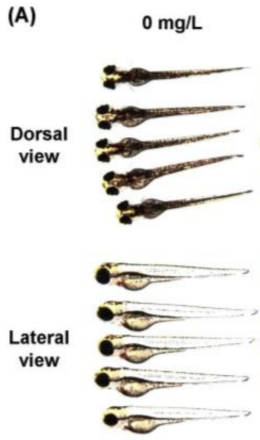

(B)

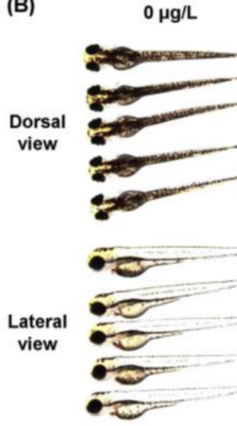

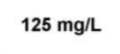
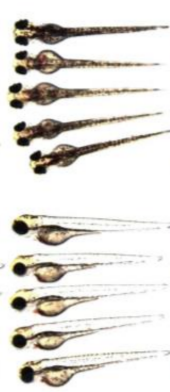

$125 \mu \mathrm{g} / \mathrm{L}$
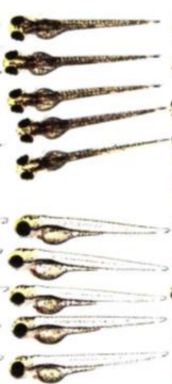

$250 \mathrm{mg} / \mathrm{L}$
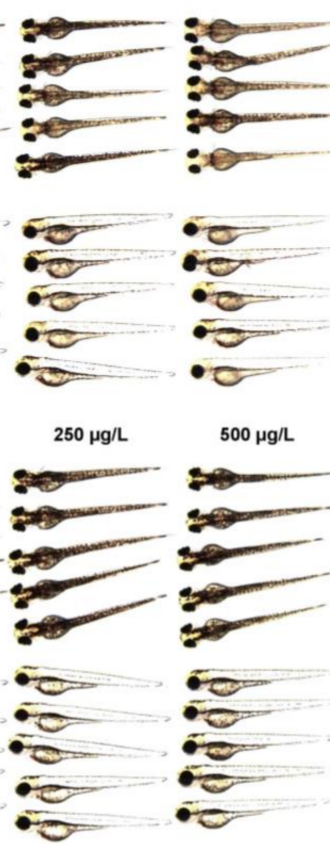

Figure 7. Cont. 
(C)

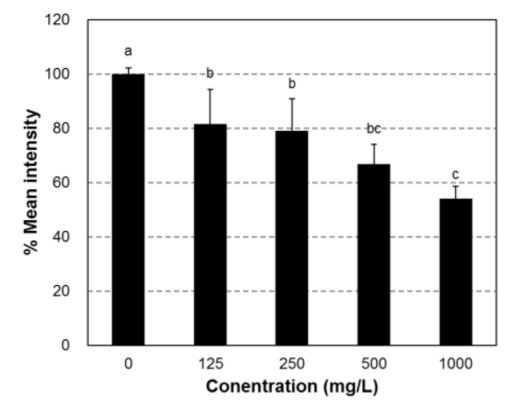

(D)

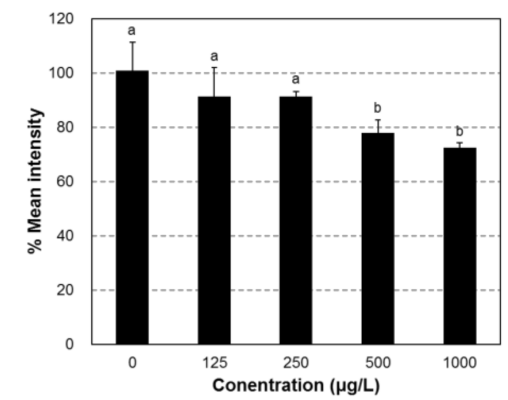

Figure 7. Pigment development in zebrafishes treated with compound \#2. Zebrafish embryos were exposed to either arbutin (A) or compound \#2 (B) at indicated doses for $72 \mathrm{~h}$. Upper, dorsal view; lower, lateral view. Pigmentation in zebrafish after exposure to arbutin (C) or compound \#2 (D) was quantitatively measured. $n=5$; error bars, mean \pm SD. Different alphabetical letters indicate significant differences among the conditions $(p<0.05)$.

\section{Discussion}

The present study examined the anti-melanogenic potential of novel synthetic compounds for cosmetic purpose. Based on the previous in silico study by the docking simulation implicating triene analogs as pharmacophores inhibiting tyrosinase [16], we hypothesized that 1,6-diphenyl-1,3,5-hexatriene and its derivatives may impede the process of melanogenesis. The hypothesis was examined in the following three ways. First, a total of 25 triene analogs were screened for their cytotoxic effects on melanocytes and inhibitory effect on melanogenesis. Second, the compounds with low cytotoxicity and high anti-melanogenesis activity were selected and evaluated for their abilities to suppress the expression of melanogenic factors in B16F10 murine melanoma cells. The third, compound (\#2) that exhibited the most effective anti-melanogenesis activity was further examined for its in vivo anti-melanogenic effect in zebrafish.

Multiple reports have demonstrated that tyrosinase may be catalytically inhibited by aromatic acids such as benzoic acid and cinnamic acid as well as their derivatives [11,17-19]. Furthermore, 1,6-diphenyl-1,3,5-hexatriene and its derivatives are likely to efficiently penetrate into the lipid bilayer in skin because of their hydrophobicity [20]. In addition, $\mathrm{Ha}$ and colleagues reported that synthetic compounds containing triene analogs have stronger tyrosinase inhibitory effect than compounds containing benzene analogs [16]. Therefore, compounds \#2, \#4, and \#6, which are 1,6-diphenyl-1,3,5-hexatriene derivatives, may easily cross the lipid bilayer of skin cells, dock to tyrosinase in the melanocytes, and inhibit its activity. However, the mechanism through which these synthetic molecules are metabolized in the melanocytes remains to be further unraveled.

As expected from QSAR analysis, most of the synthetic compounds tested in this study were non-toxic to B16F10 mouse melanoma cells. In particular, compounds \#2, \#4, and \#6 reduced $\alpha$-MSH-induced melanin synthesis in a dose-dependent manner and their inhibitory effects on the activity of mushroom tyrosinase were comparable with the effect of kojic acid at concentrations of $\leq 12.5 \mu \mathrm{M}$. Among the three compounds, compound \#2 was the most effective and abrogated $\alpha$-MSH-induced increase in mRNA and protein expression of melanogenic factors such as MITF, TYR, TYRP1, and TYRP2 in B16F10 cells. It is well-known that TYR is modulated by MITF, a master transcription factor in melanogenesis, and that TYRP1 and TYRP2 are major targets of MITF-mediated melanogenic enzymes [21-23]. During melanin synthesis, tyrosine undergoes TYR-dependent conversion and is catalyzed to dopaquinone and subsequently dopachrome. TYRP2 converts dopachrome to 5,6-dihydroxyindole-2-carboxylic acid (DHICA), whereas TYRP1 oxidizes DHICA to a carboxylated indole-quinone, which is eventually converted into melanin [24]. Thus, our results suggest that compound \#2, which suppressed MITF-mediated melanogenic enzyme expression, has a great potential as an anti-melanogenic agent. 
The anti-melanogenic effect of compound $\mathbf{\# 2}$ was further verified in vivo using zebrafish embryos. Zebrafish are useful as a vertebrate model system to investigate the depigmentation activity of melanogenic regulatory compounds [25]. In this study, zebrafish embryos were treated with compound \#2 at various doses for $72 \mathrm{~h}$. The significant reduction in body pigmentation was observed in a dose-dependent manner without oral toxicity during the experimental period. Although this observation supports the anticipated anti-melanogenic effect of compound \#2 on human melanocytes, further study is essential to examine whether the compound is affordable to manufacture for commercial purpose.

Taken together, we have evaluated the inhibitory activity of a variety of (1E,3E,5E)-1,6-bis(substituted phenyl)hexa-1,3,5-triene analogs on melanin synthesis in B16F10 cells and zebrafish embryos. Among the three 1,6-diphenyl-1,3,5-hexatriene derivatives that effectively decreased $\alpha-\mathrm{MSH}$-induced melanogenesis, compound \#2 was found to suppress the mRNA and protein expression of melanogenic enzymes in vitro and in vivo. These findings suggest that this compound may be used as a potent anti-melanogenic agent for cosmetic purposes.

\section{Materials and Methods}

\subsection{Preparation of Synthetic Compounds}

A total of 25 synthetic compounds, 1,6-diphenyl-1,3,5-hexatriene and its derivatives, were synthesized, as previously described (Supplementary Figure S1) [16] with minor modifications. The synthetic details were described in Supplementary Table S1. The toxicity of each synthetic compound was in silico assayed using three-dimensional quantitative structure-activity relationship (3D-QSAR) methods [26] in Derek ${ }^{\mathrm{TM}}$ Nexus system (Lhasa Limited; Leeds, UK) [27]. To construct 3D-QSAR models, structural alignment and comparative molecular field analysis (CoMFA) were performed on the synthetic compounds for their predictive effectiveness in tyrosinase inhibition. The compounds were dissolved in dimethyl sulfoxide (DMSO; Sigma-Aldrich, St. Louis, MO, USA) at $100 \mathrm{mM}$ concentration and freshly diluted in culture media.

\subsection{Cell Culture}

Mouse melanoma cell line, B16F10, was obtained from the Korean Cell Line Bank (Seoul, Korea). The cells were cultured in Dulbecco's modified Eagle's medium (DMEM) supplemented with $10 \%$ fetal bovine serum (FBS), penicillin $(100 \mathrm{IU} / \mathrm{mL})$, and streptomycin $(100 \mathrm{mg} / \mathrm{mL})$ (all from Invitrogen, Carlsbad, CA, USA). For sub-cultivation, cells were rinsed in phosphate-buffered saline (PBS; Gibco/Life Technologies, Carlsbad, CA, USA) and detached using 0.05\% trypsin-ethylenediaminetetraacetic acid (EDTA; Gibco/Life Technologies). The cells were harvested, plated onto prepared culture dishes, and maintained in a humidified incubator $\left(37^{\circ} \mathrm{C}\right.$, $\left.5 \% \mathrm{CO}_{2}\right)$.

\subsection{Determination of Cytotoxicity}

To test the cytotoxicity of each extract, cell counting kit-8 (CCK-8; Dojindo Laboratories, Kumamoto, Japan) was used, as previously described [28]. B16F10 cells were plated at a density of $5 \times 10^{3}$ cells/well in a 96-well plate (Nunc ${ }^{\text {TM}}$; Thermo Fisher Scientific, Waltham, MA, USA) and incubated with various concentrations of each compound for $24 \mathrm{~h}$ or $72 \mathrm{~h}$. CCK-8 assay was performed as per manufacturer's instructions. The absorbance, which is proportional to the number of living cells in each well, was measured at $450 \mathrm{~nm}$ wavelength using a microplate reader (Sunrise ${ }^{\mathrm{TM}}$, Tecan Group Ltd., Männedorf, Switzerland).

\subsection{Determination of Relative Melanin Contents}

B16F10 cells were plated at a density of $2 \times 10^{6}$ cells in a $100 \mathrm{~mm}$ culture dish (Nunc ${ }^{\mathrm{TM}}$; Thermo Fisher Scientific) and treated with the compound at 1 or $2 \mu \mathrm{M}$ and/or alpha-melanocyte-stimulating 
hormone ( $\alpha-\mathrm{MSH})$ for $72 \mathrm{~h}$. The cells were harvested after rinsing with PBS and the cell pellet was placed in $1 \mathrm{~N}$ sodium hydroxide $(\mathrm{NaOH})$ for $20 \mathrm{~min}$ at $80^{\circ} \mathrm{C}$ to solubilize melanin. The melanin content was determined by measuring the absorbance of the supernatant at $490 \mathrm{~nm}$ wavelength. The protein content in the supernatant was determined by Bradford assay using bovine serum albumin (BSA) as the protein standard [29]. The melanin content was adjusted by the amount of protein in the same reaction. The results were expressed as the percentage of the control.

\subsection{Measurement of Tyrosinase Inhibitory Activity}

In vitro tyrosinase activity was examined by measuring the rate of oxidation of L-DOPA (Sigma-Aldrich) [30] with minor modifications. In $840 \mu \mathrm{L}$ of $100 \mathrm{mM}$ phosphate buffer ( $\mathrm{pH} 7.0$ ) in the absence or presence of $50 \mu \mathrm{L}$ of sample diluents, $50 \mu \mathrm{L}$ of mushroom tyrosinase $(2000 \mathrm{U} / \mathrm{mL}$; Sigma-Aldrich) or B16F10 cell homogenates $(3 \mathrm{mg} / \mathrm{mL})$ was added and incubated at $37^{\circ} \mathrm{C}$ for $5 \mathrm{~min}$. Subsequently, $60 \mu \mathrm{L}$ of $10 \mathrm{mM}$ L-DOPA was added to yield a final concentration of $0.6 \mathrm{mM}$. The mixture was then allowed to react for $15 \mathrm{~min}$ (with mushroom tyrosinase) or $60 \mathrm{~min}$ (with cell homogenates). The reaction was monitored at $475 \mathrm{~nm}$ wavelength. A control reaction was performed with DMSO. The percentage of inhibition of tyrosinase activity was calculated as inhibition $(\%)=(\mathrm{A}-\mathrm{B}) / \mathrm{A} \times 100$, where A represents the difference in the absorbance of the control between the incubation time of 5 and $20 \mathrm{~min}$ and $\mathrm{B}$ represents the difference in the absorbance of the test sample between the incubation time of 5 and $20 \mathrm{~min}$. Resveratrol $(10 \mu \mathrm{M})$ was used as a positive standard [31].

\subsection{Quantitative Polymerase Chain Reaction ( $q P C R$ ) Analysis}

Total RNA extracts were prepared from the harvested cells using a column-based isolation kit (RNeasy Mini Kit; Qiagen, Hilden, Germany) according to the manufacturer's instructions [32]. After quantification at $260 \mathrm{~nm}$ wavelength, RNA $(0.5 \mu \mathrm{g})$ was reverse-transcribed to cDNA using Moloney murine leukemia virus (M-MLV) reverse transcriptase (Thermo Fisher Scientific) with oligo(dT) $)_{12-18}$ primer. To analyze the relative mRNA levels for each gene, SYBR Green-based real-time PCR was performed using LightCycler ${ }^{\circledR}$ Multiplex Masters (Roche, Basel, Switzerland) with the designated primer sets (Table 1) on LightCycler ${ }^{\circledR}$ Nano Instrument (Roche). The transcript expression levels were normalized with the expression level of $\beta$-actin.

Table 1. Primer sets for real-time PCR.

\begin{tabular}{|c|c|c|c|}
\hline \multirow{2}{*}{ Gene (NCBI Accession No.) } & \multicolumn{2}{|c|}{ Primer $\left(5^{\prime} \rightarrow 3^{\prime}\right)$} & \multirow{2}{*}{ Product Length (bp) } \\
\hline & Forward & Reverse & \\
\hline $\begin{array}{c}\text { Tyr } \\
\text { (NM_011661) }\end{array}$ & СCTCCTGGCAGATCATTTGT & GGCAAATCCTTCCAGTGTGT & 236 \\
\hline $\begin{array}{c}\text { Tyrp1 } \\
\text { (NM_001282015) }\end{array}$ & CTTGGAGGTCCGTGTATTTG & GACCGCATCAGTGAAAGTGT & 223 \\
\hline $\begin{array}{c}\text { Tyrp2 } \\
\left(\mathrm{NM} \_010024\right)\end{array}$ & TACCATCTGTTGTGGCTGGA & CAAGCTGTCGCACACAATCT & 204 \\
\hline $\begin{array}{c}\text { Mitf } \\
\text { (NM_001178049) }\end{array}$ & AGGACCTTGAAAACCGACAG & GTGGATGGGATAAGGGAAAG & 115 \\
\hline $\begin{array}{c}\beta \text {-actin } \\
\text { (NM_007393) }\end{array}$ & ACTATTGGCAACGAGCGGTT & ATGGATGCCACAGGATTCCA & 81 \\
\hline
\end{tabular}

\subsection{Western Blot Analysis}

Cultured cells were collected, rinsed, and subjected to NE-PER ${ }^{\circledR}$ Nuclear and Cytoplasmic Extraction Reagents (Thermo Fisher Scientific) as previously described [32,33]. After protein quantification by Bradford assay, proteins were separated by $12 \%$ sodium dodecyl sulfate polyacrylamide gel electrophoresis (SDS-PAGE) and transferred onto a polyvinylidene fluoride 
(PVDF) membrane. Primary antibodies used in this study were as follows: rabbit anti-microphthalmia-associated transcription factor (MITF; Abcam, Cambridge, UK), goat anti-lamin B, mouse anti-tyrosinase (TYR), mouse anti-tyrosinase-related protein 1 (TYRP1), mouse anti-TYRP2, and mouse anti- $\beta$-actin (Santa Cruz Biotechnology, Inc., Dallas, TX, USA). Secondary antibodies used were anti-mouse, anti-rabbit, or anti-goat IgG conjugated to horseradish peroxidase (Santa Cruz Biotechnology, Inc.). Protein bands were visualized using the SuperSignal ${ }^{\circledR}$ West Pico Chemiluminescent Substrate kit (Thermo Fisher Scientific) and ImageQuant LAS 4000 mini (GE Healthcare Life Sciences, Little Chalfont, UK). Digital images were analyzed for densitometry using Image Studio ${ }^{\mathrm{TM}}$ Lite software (LI-COR Corp., Lincoln, NE, USA).

\subsection{Determination of Depigmentation in Zebrafish}

The study was conducted in accordance with the guidelines of the Institutional Animal Care and Use Committee of the Korea Institute of Toxicology, Daejeon, Korea (permission number: 1604-0112; approved on 2 April 2017). Wild-type adult zebrafish (6-24-month-old) were cultured at the Systems Toxicology Research Center, Korea Institute of Toxicology. These were maintained under standard conditions (carbon-filtered dechlorinated tap water at $27 \pm 1{ }^{\circ} \mathrm{C}$ with $14 / 10 \mathrm{~h}$ light/dark cycle), as previously described [34,35]. To test the anti-melanogenic effect of the selected compounds, the embryos were collected and exposed to the compounds at designated concentrations $(0,125,250,500$, and $1000 \mu \mathrm{g} / \mathrm{L})$. After $72 \mathrm{~h}$ of incubation, pigment development in zebrafish was observed under a microscope (Leica M205 FA, Leica, Wetzlar, Germany). Arbutin was used as a positive standard at concentrations of $0,125,250,500$, and $1000 \mathrm{mg} / \mathrm{L}$. The obtained images of pigment area density were quantitatively analyzed using ImageJ software, $1.48 \mathrm{v}$ (developed at the National Institutes of Health), and normalized to those of the control

\subsection{Statistical Analysis}

The obtained data were analyzed by one-way analysis of variance (ANOVA) using SPSS statistics 22 software (SPSS Inc., Chicago, IL, USA). Statistical differences among experimental groups were determined by one-way ANOVA, followed by Duncan's multiple range test at $5 \%$ significance level. Statistical difference $(p<0.05)$ among values was marked with different alphabetical letters.

Supplementary Materials: Supplementary materials can be found at http:/ /www.mdpi.com/1422-0067/19/4/1067/ s1.

Acknowledgments: This work was supported by the Technological Innovation R \& D Program, funded by the Ministry of Small and Medium-sized Enterprises (SMEs) and Startups, Republic of Korea (grant number: C0406345).

Author Contributions: Jisun Oh: experimental design, data analysis and interpretation, and manuscript writing; Jungeun Kim: cell culture, in vitro assays, data collection, and analysis; Jin Ho Jang: cell culture, in vitro assays and data collection; Sangwoo Lee: in vivo assays using zebrafish, data collection, and analysis; Chul Min Park: compound synthesis and in silico assays; Woo-Keun Kim: experimental conception, financial support and corresponding author; Jong-Sang Kim: experimental conception, final approval of the manuscript, and corresponding author.

Conflicts of Interest: The authors declare no conflict of interest.

\section{References}

1. Schallreuter, K.U.; Kothari, S.; Chavan, B.; Spencer, J.D. Regulation of melanogenesis-Controversies and new concepts. Exp. Dermatol. 2008, 17, 395-404. [CrossRef] [PubMed]

2. Rinnerthaler, M.; Bischof, J.; Streubel, M.K.; Trost, A.; Richter, K. Oxidative stress in aging human skin. Biomolecules 2015, 5, 545-589. [CrossRef] [PubMed]

3. Natarajan, V.T.; Ganju, P.; Ramkumar, A.; Grover, R.; Gokhale, R.S. Multifaceted pathways protect human skin from UV radiation. Nat. Chem. Biol. 2014, 10, 542-551. [CrossRef] [PubMed]

4. Baldea, I.; Mocan, T.; Cosgarea, R. The role of ultraviolet radiation and tyrosine stimulated melanogenesis in the induction of oxidative stress alterations in fair skin melanocytes. Exp. Oncol. 2009, 31, 200-208. [PubMed] 
5. Solano, F.; Briganti, S.; Picardo, M.; Ghanem, G. Hypopigmenting agents: An updated review on biological, chemical and clinical aspects. Pigment Cell Melanoma Res. 2006, 19, 550-571. [CrossRef] [PubMed]

6. Ando, H.; Kondoh, H.; Ichihashi, M.; Hearing, V.J. Approaches to identify inhibitors of melanin biosynthesis via the quality control of tyrosinase. J. Investig. Dermatol. 2007, 127, 751-761. [CrossRef] [PubMed]

7. Kim, Y.J.; Uyama, H. Tyrosinase inhibitors from natural and synthetic sources: Structure, inhibition mechanism and perspective for the future. Cell. Mol. Life Sci. 2005, 62, 1707-1723. [CrossRef] [PubMed]

8. Parvez, S.; Kang, M.; Chung, H.S.; Bae, H. Naturally occurring tyrosinase inhibitors: Mechanism and applications in skin health, cosmetics and agriculture industries. Phytother. Res. 2007, 21, 805-816. [CrossRef] [PubMed]

9. Pillaiyar, T.; Manickam, M.; Namasivayam, V. Skin whitening agents: Medicinal chemistry perspective of tyrosinase inhibitors. J. Enzym. Inhib. Med. Chem. 2017, 32, 403-425. [CrossRef] [PubMed]

10. Chang, T.S. An updated review of tyrosinase inhibitors. Int. J. Mol. Sci. 2009, 10, 2440-2475. [CrossRef] [PubMed]

11. Loizzo, M.R.; Tundis, R.; Menichini, F. Natural and synthetic tyrosinase inhibitors as antibrowning agents: An update. Compr Rev. Food Sci. Food Saf. 2012, 11, 378-398. [CrossRef]

12. Cabanes, J.; Chazarra, S.; Garciacarmona, F. Kojic acid, a cosmetic skin whitening agent, is a slow-binding inhibitor of catecholase activity of tyrosinase. J. Pharm. Pharmacol. 1994, 46, 982-985. [CrossRef] [PubMed]

13. Chakraborty, A.K.; Funasaka, Y.; Komoto, M.; Ichihashi, M. Effect of arbutin on melanogenic proteins in human melanocytes. Pigment Cell Melanoma Res. 1998, 11, 206-212. [CrossRef]

14. Palumbo, A.; d'Ischia, M.; Misuraca, G.; Prota, G. Mechanism of inhibition of melanogenesis by hydroquinone. Biochim. Biophys. Acta 1991, 1073, 85-90. [CrossRef]

15. Shimogaki, H.; Tanaka, Y.; Tamai, H.; Masuda, M. In vitro and in vivo evaluation of ellagic acid on melanogenesis inhibition. Int. J. Cosmet. Sci. 2000, 22, 291-303. [CrossRef] [PubMed]

16. Ha, Y.M.; Lee, H.J.; Park, D.; Jeong, H.O.; Park, J.Y.; Park, Y.J.; Lee, K.J.; Lee, J.Y.; Moon, H.R.; Chung, H.Y. Molecular docking studies of (1E,3E,5E)-1,6-bis(substituted phenyl)hexa-1,3,5-triene and 1,4-bis(substituted trans-styryl)benzene analogs as novel tyrosinase inhibitors. Biol. Pharm. Bull. 2013, 36, 55-65. [CrossRef] [PubMed]

17. Shi, Y.; Chen, Q.X.; Wang, Q.; Song, K.K.; Qiu, L. Inhibitory effects of cinnamic acid and its derivatives on the diphenolase activity of mushroom (Agaricus bisporus) tyrosinase. Food Chem. 2005, 92, 707-712. [CrossRef]

18. Kermasha, S.; Goetghebeur, M.; Monfette, A.; Metche, M.; Rovel, B. Studies on Inhibition of Mushroom Polyphenol Oxidase Using Chlorogenic Acid as Substrate. J. Agric. Food Chem. 1993, 41, 526-531. [CrossRef]

19. Robert, C.; Rouch, C.; Cadet, F. Inhibition of palmito (Acanthophoenix rubra) polyphenol oxidase by carboxylic acids. Food Chem. 1997, 59, 355-360. [CrossRef]

20. Davenport, L.; Dale, R.E.; Bisby, R.H.; Cundall, R.B. Transverse location of the fluorescent probe 1,6-diphenyl-1,3,5-hexatriene in model lipid bilayer membrane systems by resonance excitation energy transfer. Biochemistry 1985, 24, 4097-4108. [CrossRef] [PubMed]

21. Tachibana, M. MITF: A stream flowing for pigment cells. Pigment Cell Melanoma Res. 2000, 13, $230-240$. [CrossRef]

22. Videira, I.F.; Moura, D.F.; Magina, S. Mechanisms regulating melanogenesis. An. Bras. Dermatol. 2013, 88, 76-83. [CrossRef] [PubMed]

23. Park, H.Y.; Kosmadaki, M.; Yaar, M.; Gilchrest, B.A. Cellular mechanisms regulating human melanogenesis. Cell. Mol. Life Sci. 2009, 66, 1493-1506. [CrossRef] [PubMed]

24. Slominski, A.; Tobin, D.J.; Shibahara, S.; Wortsman, J. Melanin pigmentation in mammalian skin and its hormonal regulation. Physiol. Rev. 2004, 84, 1155-1228. [CrossRef] [PubMed]

25. Choi, T.Y.; Kim, J.H.; Ko, D.H.; Kim, C.H.; Hwang, J.S.; Ahn, S.; Kim, S.Y.; Kim, C.D.; Lee, J.H.; Yoon, T.J. Zebrafish as a new model for phenotype-based screening of melanogenic regulatory compounds. Pigment Cell Melanoma Res. 2007, 20, 120-127. [CrossRef] [PubMed]

26. Raies, A.B.; Bajic, V.B. In silico toxicology: Computational methods for the prediction of chemical toxicity. Wiley Interdiscip. Rev. Comput. Mol. Sci. 2016, 6, 147-172. [CrossRef] [PubMed]

27. Marchant, C.A.; Briggs, K.A.; Long, A. In silico tools for sharing data and knowledge on toxicity and metabolism: Derek for windows, meteor, and vitic. Toxicol. Mech. Methods 2008, 18, 177-187. [CrossRef] [PubMed] 
28. Oh, J.; Jeon, S.B.; Lee, Y.; Lee, H.; Kim, J.; Kwon, B.R.; Yu, K.Y.; Cha, J.D.; Hwang, S.M.; Choi, K.M.; Jeong, Y.S. Fermented red ginseng extract inhibits cancer cell proliferation and viability. J. Med. Food 2015, 18, 421-428. [CrossRef] [PubMed]

29. Bradford, M.M. A rapid and sensitive method for the quantitation of microgram quantities of protein utilizing the principle of protein-dye binding. Anal. Biochem. 1976, 72, 248-254. [CrossRef]

30. Masamoto, Y.; Ando, H.; Murata, Y.; Shimoishi, Y.; Tada, M.; Takahata, K. Mushroom tyrosinase inhibitory activity of esculetin isolated from seeds of Euphorbia lathyris L. Biosci. Biotechnol. Biochem. 2003, 67, 631-634. [CrossRef] [PubMed]

31. Satooka, H.; Kubo, I. Resveratrol as a kcat type inhibitor for tyrosinase: Potentiated melanogenesis inhibitor. Bioorg. Med. Chem. 2012, 20, 1090-1099. [CrossRef] [PubMed]

32. Woo, Y.; Oh, J.; Kim, J.S. Suppression of Nrf2 activity by chestnut leaf extract increases chemosensitivity of breast cancer stem cells to paclitaxel. Nutrients 2017, 9, 760. [CrossRef] [PubMed]

33. Seo, H.; Oh, J.; Hahn, D.; Kwon, C.S.; Lee, J.S.; Kim, J.S. Protective effect of glyceollins in a mouse model of dextran sulfate sodium-induced colitis. J. Med. Food 2017, 20, 1055-1062. [CrossRef] [PubMed]

34. Choi, J.S.; Kim, R.O.; Yoon, S.; Kim, W.K. Developmental toxicity of zinc oxide nanoparticles to zebrafish (Danio rerio): A transcriptomic analysis. PLoS ONE 2016, 11, e0160763. [CrossRef] [PubMed]

35. Chen, W.C.; Tseng, T.S.; Hsiao, N.W.; Lin, Y.L.; Wen, Z.H.; Tsai, C.C.; Lee, Y.C.; Lin, H.H.; Tsai, K.C. Discovery of highly potent tyrosinase inhibitor, T1, with significant anti-melanogenesis ability by zebrafish in vivo assay and computational molecular modeling. Sci. Rep. 2015, 5, 7995. [CrossRef] [PubMed]

(C) 2018 by the authors. Licensee MDPI, Basel, Switzerland. This article is an open access article distributed under the terms and conditions of the Creative Commons Attribution (CC BY) license (http:/ / creativecommons.org/licenses/by/4.0/). 